\title{
New Results on the Exponential Stability of Class Neural Networks with Time-Varying Lags
}

\author{
Yener ALTUN* \\ Van Yüzüncü Yıl Üniversitesi, Matematik Bölümü, Van \\ (ORCID: 0000-0003-1073-5513)
}

\begin{abstract}
In this article, some novel approaches to the analysis of global exponential stability (GES) for a class of neural networks with time-varying lags are presented. For functional differential equations, these approaches to are based on Lyapunov stability theory. Then, the necessary and sufficient conditions for GES of the equation considered have been discussed. An example was given to illustrate the qualitative behavior of the solution of the proposed equation and MATLAB-Simulink Program was used to demonstrate the validity of the results obtained in this sample. Consequently, the obtained results include and improve the results found in the related literature.
\end{abstract}

Keywords: Neural networks, GES, Lyapunov functional, Convergence rate.

\section{Zaman Değişken Gecikmelerle Sınıfsal Sinir Ăglarının Üstel Kararlılığı Üzerine Yeni Sonuçlar}

\begin{abstract}
$\ddot{\mathbf{O z}}$
$\mathrm{Bu}$ makalede, zamanla değişen gecikmelerle sinir ağlarının bir sınıfi için global üstel kararlılığının analizine yönelik bazı yeni yaklaşımlar sunulmuştur. Fonksiyonel diferansiyel denklemlere yönelik bu yaklaşımlar için Lyapunov kararlılık teorisinden yararlanılmıştır. Daha sonra, dikkate alınan denklemin global üstel kararlılığ (GÜK) için gerek ve yeter koşullar tartışılmıştır. Önerilen denklemin çözümünün nitel davranışını göstermek için bir örnek verilmiştir ve bu örneklerde elde edilen sonuçların geçerliliğini göstermek için MATLAB-Simulink Programı kullanılmıştır. Sonuç olarak, elde edilen sonuçlar ilgili literatürde bulunan sonuçları içerir ve geliştirir.
\end{abstract}

Anahtar kelimeler: Sinir ağları, GÜK, Lyapunov fonksiyoneli, Yakınsama oranı.

\section{Introduction}

It should be noted that time-varying lags are often encountered in different neural networks. These timevarying delays are frequently examined in qualitative behaviors of neural networks, such as optimization, stability, and instability. When examining the qualitative behavior of neural networks, the stability conditions that bring the restriction conditions to the network parameters are obtained depending on the desired applications. Thus, when a neural network is used to solve problems, the neural network must have a equilibrium point independent of the initial conditions. It should be noted that the assumptions to be applied to the network parameters of a neural network are determined by the characters of the functions considered. Lately, the dynamic properties of neural networks, particularly the stability, instability, oscillation and asymptotic behaviors of neural networks have been received considerable account by many researchers (see, for instance, [1-18] and the references therein). In 2009, Li [12] considered a class of neural networks defined as follows 
$\frac{d}{d t}[x(t)+p x(t-\tau)]+a x(t)-b \tanh x(t-\sigma)=0, \quad t \geq t_{0} \geq 0$,

where $a, b, \tau$ and $\sigma$ are positive real constants $|p|<1$. Using Lyapunov functional, the author established some conditions for the GES of solutions of (1). By this work, the author established an improved criterion for the GES of solutions of (1).

In the relevant literature, some conclusions can be reached regarding the qualitative properties of the neutral-type neural networks (see for instance, Agarwal and Grace [1], Altun and Tunç [2], ElMorshedy and Gopalsamy [5], Park [14], Park and Kwon [15], Tunç [16] and the references therein). The authors often used from several techniques such as Lyapunov-functional method, model transformations and linear matrix inequality to obtain some new necessary and sufficient conditions to ensure the stability and asymptotic stability of equation (1).

The Lyapunov method, which we will benefit from in this study, is used as a basic tool for examining the qualitative behaviors of differential equations and systems. The main advantage of these methods allows us to mention about their qualitative behavior without any knowledge of about the solutions. The basis of these methods is based on the construction of an appropriate function for the equation or system under examination. We will use this method for the equation (2) which we will discuss below.

In this paper, instead of (1), we take into account a class of neural networks defined by nonlinear equation system as follows

$$
\frac{d}{d t}[x(t)+p(t) x(t-\tau(t)]+q(t) h(x(t))-r(t) \tanh x(t-\sigma(t))=0
$$

where $p, q, r:\left[t_{0}, \infty\right) \rightarrow[0, \infty), t_{0} \geq 0$, and $h: \mathfrak{R} \rightarrow \mathfrak{R}$ are continuous functions with $h(0)=0$; $p$ is also differentiable, and $|p(t)| \leq p_{0}<1,\left(p_{0}\right.$-constant). The variable delays $\tau(t)$ and $\sigma(t)$ are continuous differentiable functions, defined by $\tau(t):[0, \infty) \rightarrow\left[0, \tau_{0}\right]$ and $\sigma(t):[0, \infty) \rightarrow\left[0, \sigma_{0}\right]$ satisfying

$$
0 \leq \tau(t) \leq \tau_{0}, \quad 0 \leq \sigma(t) \leq \sigma_{0}, \quad \tau^{\prime}(t) \leq \delta_{1}<1, \quad \sigma^{\prime}(t) \leq \delta_{2}<1 .
$$

Throughout the paper, we assume that assumptions given by (3) hold.

For each solution of (2), we suppose existence of the following initial condition

$$
x_{0}(\theta)=\phi(\theta), \quad \theta \in[-\vartheta, 0],
$$

where $\vartheta=\max \left\{\tau_{0}, \sigma_{0}\right\}, \phi \in C([-\vartheta, 0] ; \mathfrak{R})$.

The function $h_{1}(x)$ is defined as follows

$$
h_{1}(x)= \begin{cases}\frac{h(x)}{x}, & x \neq 0 \\ h^{\prime}(0), & x=0 .\end{cases}
$$

Hence, taking into account condition (4), the equation (2) can be rewritten as follows

$$
\frac{d}{d t}\left[x(t)+p(t) x(t-\tau(t)]+q(t) h_{1}(x(t)) x(t)-r(t) \tanh x(t-\sigma(t))=0\right.
$$


It should be well known that GES has an important place in many areas of applications and designs of neural networks, engineering fields, automatic control, biological systems and synchronization in secure communication [11-13]. Therefore, GES question of equation (5) is very important from both theoretical and practical viewpoints. The result obtained here contributes to the subject in the related literature and it may be beneficial for authors working on the behaviors of the equation considered with variable lags. Especially, this exponential stability can also be applied to some type of delayed equations [3].

The main aim of this study is firstly to examine the qualitative behaviors of solutions of equation (5) and to present some novel approaches ensuring GES of this equation by utilizing Lyapunov functional. Then an instance is given to illustrate the applicability and usefulness of the results obtained. Finally, we used MATLAB-Simulink Program to show the qualitative behaviors of the solution of the proposed equation system.

The following Lemma is required to prove the main result of this article.

Lemma 1. ([2]) Let $N$ be a symmetric matrix positive definite and $a, b \in \mathfrak{R}^{n}$. Then, for $\forall N \in \mathfrak{R}^{n \times n}$, we have

$$
\pm 2 a^{T} b \leq a^{T} N a+b^{T} N^{-1} b
$$

\section{Main Results}

We suppose that there exist non-negative real numbers $q_{1}, q_{2}, r_{1}, r_{2}, n_{1}$ and $n_{2}$ such that for $t \geq t_{0}$,

$$
q_{1} \leq q(t) \leq q_{2}, \quad r_{1} \leq r(t) \leq r_{2}, \quad n_{1} \leq h_{1}(x) \leq n_{2} .
$$

In this section, the GES of the equation discussed under some sufficient conditions is presented as follows.

Theorem 1. Suppose that $q_{1} n_{1}\left(1-p_{0}\right)>r_{2}\left(1+p_{0}\right)$. Then the zero solution of (5) is globally exponentially stable.

Proof. Since $q_{1} n_{1}\left(1-p_{0}\right)>r_{2}\left(1+p_{0}\right)$, we can choose the proper constants $\alpha, \beta$ as follows such that

and

$$
p_{0}\left(q_{1} n_{1}+r_{2}\right)<\alpha, \quad r_{2}\left(1+p_{0}\right)<\beta
$$

$$
\alpha+\beta<2 q_{1} n_{1}-q_{1} n_{1} p_{0}-r_{2}
$$

Thus, there exist $\varepsilon_{1}, \varepsilon_{2}, \varepsilon_{3}>0$ such that

$$
2 \varepsilon_{1} p_{0}^{2}+p_{0}\left(q_{1} n_{1}+r_{2}\right) \leq\left(1-\delta_{1}\right) \alpha e^{-\varepsilon_{1} \tau_{0}}, \quad r_{2}\left(1+p_{0}\right) \leq\left(1-\delta_{2}\right) \beta e^{-\varepsilon_{2} \sigma_{0}}
$$

And

$2 \varepsilon_{3}+\alpha+\beta \leq 2 q_{1} n_{1}-p_{0} q_{1} n_{1}-r_{2}$.

Considering the assumption $|p(t)| \leq p_{0}<1$, there also exists a positive constant $\varepsilon_{4}$ such that

$$
|p(t)| \leq p_{0}<e^{-\frac{\varepsilon_{4}}{2} \tau_{0}} .
$$

Let $\varepsilon^{*}=\min \left\{\varepsilon_{1}, \varepsilon_{2}, \varepsilon_{3}, \varepsilon_{4}\right\}$, then we can indicate that, for any initial data $\phi \in C\left(\left[-\max \left\{\tau_{0}, \sigma_{0}\right\}, 0\right], \mathfrak{R}\right)$, there exists a number $M \geq 1$ such that 


$$
\mid x\left(t, t_{0}, \phi\right)+p(t) x\left(t-\tau(t) \mid \leq M\|\phi\|_{\left(\tau_{0}, \sigma_{0}\right)} e^{-\frac{\varepsilon^{*}}{2}\left(t-t_{0}\right)},\right.
$$

where $\|\phi\|_{\left(\tau_{0}, \sigma_{0}\right)}=\sup _{-\max \left\{\tau_{0}, \sigma_{0}\right\}}|\phi(s)|$.

In order to show this, we describe a new Lyapunov functional as follows:

$$
V(t)=e^{\varepsilon^{*} t}[x(t)+p(t) x(t-\tau(t))]^{2}+\alpha \int_{t-\tau(t)}^{t} e^{\varepsilon^{*} s} x^{2}(s) d s+\beta \int_{t=\sigma(t)}^{t} e^{\varepsilon^{*} s} \tanh ^{2} x(s) d s,
$$

which implies that

$$
\begin{aligned}
V\left(t_{0}\right) & \leq e^{\varepsilon^{*} t_{0}}\|\phi\|_{\left(\tau_{0}, \sigma_{0}\right)}^{2}\left(1+p_{0}\right)^{2}+\alpha \tau\left(t_{0}\right) e^{\varepsilon^{*} t_{0}}\|\phi\|_{\left(\tau_{0}, \sigma_{0}\right)}^{2}+\beta \sigma\left(t_{0}\right) e^{\varepsilon^{*} t_{0}}\|\phi\|_{\left(\tau_{0}, \sigma_{0}\right)}^{2} \\
& \leq e^{\varepsilon^{*} t_{0}}\|\phi\|_{\left(\tau_{0}, \sigma_{0}\right)}^{2}\left\{\left(1+p_{0}\right)^{2}+\alpha \tau_{0}+\beta \sigma_{0}\right\} .
\end{aligned}
$$

The following equality is obtained when the derivative of $V$ along solutions of (5) is taken and the necessary algebraic operations are performed:

$$
\begin{aligned}
\frac{d V(t)}{d t}= & e^{\varepsilon^{*} t} \varepsilon^{*}[x(t)+p(t) x(t-\tau(t))]^{2}+2 e^{\varepsilon^{*} t}[x(t)+p(t) x(t-\tau(t))] \\
& \times\left[-q(t) h_{1}(x(t)) x(t)+r(t) \tanh x(t-\sigma(t))\right] \\
& +\alpha e^{\varepsilon^{*} t} x^{2}(t)-\left(1-\tau^{\prime}(t)\right) \alpha e^{\varepsilon^{*}(t-\tau(t))} x^{2}(t-\tau(t)) \\
& +\beta e^{\varepsilon^{*} t} \tanh ^{2} x(t)-\left(1-\sigma^{\prime}(t)\right) \beta e^{\varepsilon^{*}(t-\sigma(t))} \tanh ^{2} x(t-\sigma(t)) \\
= & e^{\varepsilon^{*} t} \varepsilon^{*}[x(t)+p(t) x(t-\tau(t))]^{2}+e^{\varepsilon^{*} t}\left\{-2 q(t) h_{1}(x(t)) x^{2}(t)\right. \\
& +2 r(t) x(t) \tanh x(t-\sigma(t))-2 p(t) q(t) h_{1}(x(t)) x(t) x(t-\tau(t)) \\
& +2 p(t) r(t) x(t-\tau(t)) \tanh x(t-\sigma(t))\} \\
& +\alpha e^{\varepsilon^{*} t} x^{2}(t)-\left(1-\tau^{\prime}(t)\right) \alpha e^{\varepsilon^{*}(t-\tau(t))} x^{2}(t-\tau(t)) \\
& +\beta e^{\varepsilon^{*} t} \tanh ^{2} x(t)-\left(1-\sigma^{\prime}(t)\right) \beta e^{\varepsilon^{*}(t-\sigma(t))} \tanh ^{2} x(t-\sigma(t)) .
\end{aligned}
$$

Using conditions (3) and (6) and the inequalities $(a+b)^{2} \leq 2\left(a^{2}+b^{2}\right)$ and $|p(t)| \leq p_{0}<1$, we can write the following inequality

$$
\begin{aligned}
\frac{d V(t)}{d t} \leq & 2 e^{\varepsilon^{*} t} \varepsilon^{*}\left[x^{2}(t)+p_{0}^{2} x^{2}(t-\tau(t))\right]+e^{\varepsilon^{*} t}\left\{-2 q_{1} n_{1} x^{2}(t)\right. \\
& +2 r_{2} x(t) \tanh x(t-\sigma(t))-2 p_{0} q_{1} n_{1} x(t) x(t-\tau(t)) \\
& \left.+2 p_{0} r_{2} x(t-\tau(t)) \tanh x(t-\sigma(t))\right\} \\
& +\alpha e^{\varepsilon^{*} t} x^{2}(t)-\left(1-\delta_{1}\right) \alpha e^{\varepsilon^{*}\left(t-\tau_{0}\right)} x^{2}(t-\tau(t)) \\
& +\beta e^{\varepsilon^{*} t} \tanh ^{2} x(t)-\left(1-\delta_{2}\right) \beta e^{\varepsilon^{*}\left(t-\sigma_{0}\right)} \tanh ^{2} x(t-\sigma(t)) .
\end{aligned}
$$

By Lemma1, and the fact that $\tanh ^{2} x(t) \leq x^{2}(t)$, we get 


$$
\begin{aligned}
\frac{d V(t)}{d t} \leq & e^{\varepsilon^{*} t}\left\{x^{2}(t)\left[2 \varepsilon^{*}-2 q_{1} n_{1}+r_{2}+p_{0} q_{1} n_{1}+\alpha+\beta\right]\right. \\
& +x^{2}(t-\tau(t))\left[2 \varepsilon^{*} p_{0}^{2}+p_{0} q_{1} n_{1}+p_{0} r_{2}-\left(1-\delta_{1}\right) \alpha e^{-\varepsilon^{*} \tau_{0}}\right] \\
& \left.+\tanh ^{2} x(t-\sigma(t))\left[r_{2}+p_{0} r_{2}-\left(1-\delta_{2}\right) \beta e^{-\varepsilon^{*} \sigma_{0}}\right]\right\},
\end{aligned}
$$

which, together with inequalities (7) and (8) yields

$$
\frac{d V(t)}{d t} \leq 0
$$

Therefore, we know that $V(t)$ is monotone non-increasing in $t$ for $t \in\left[t_{0}, \infty\right)$, that is, $V(t) \leq V\left(t_{0}\right)$. Taking into account inequality (10) and the definition of $V$, we get

$$
e^{\varepsilon^{*} t}[x(t)+p(t) x(t-\tau(t))]^{2} \leq V(t) \leq V\left(t_{0}\right) \leq e^{\varepsilon^{*} t_{0}}\|\phi\|_{\left(\tau_{0}, \sigma_{0}\right)}^{2}\left\{\left(1+p_{0}\right)^{2}+\alpha \tau_{0}+\beta \sigma_{0}\right\},
$$

i.e.,

$$
\mid x(t)+p(t) x\left(t-\tau(t) \mid \leq M\|\phi\|_{\left(\tau_{0}, \sigma_{0}\right)} e^{-\frac{\varepsilon^{*}}{2}\left(t-t_{0}\right)},\right.
$$

where $M=\sqrt{\left(1+p_{0}\right)^{2}+\alpha \tau_{0}+\beta \sigma_{0}} \geq 1$.

By (9), next we can show that $|p(t)| \leq p_{0}<e^{-\frac{\varepsilon_{4}}{2} \tau_{0}}$.

$$
|x(t)| \leq \frac{M}{1-p_{0} e^{\frac{\varepsilon^{*}}{2} \tau_{0}}}\|\phi\|_{\left(\tau_{0}, \sigma_{0}\right)} e^{-\frac{\varepsilon^{*}}{2}\left(t-t_{0}\right)}, \quad t \geq t_{0} .
$$

First, note $M \geq 1$ and (11), we have, for $t \in\left[t_{0}, t_{0}+\tau_{0}\right)$,

$$
\begin{gathered}
|x(t)| \leq|p(t)| \mid x\left(t-\tau(t) \mid+M\|\phi\|_{\left(\tau_{0}, \sigma_{0}\right)} e^{-\frac{\varepsilon^{*}}{2}\left(t-t_{0}\right)}\right. \\
\leq\|\phi\|_{\left(\tau_{0}, \sigma_{0}\right)}\left[p_{0}+M e^{-\frac{\varepsilon^{*}}{2}\left(t-t_{0}\right)}\right] \leq M\|\phi\|_{\left(\tau_{0}, \sigma_{0}\right)}\left[p_{0}+e^{-\frac{\varepsilon^{*}}{2}\left(t-t_{0}\right)}\right] \\
\leq M\|\phi\|_{\left(\tau_{0}, \sigma_{0}\right)} e^{-\frac{\varepsilon^{*}}{2}\left(t-t_{0}\right)}\left[p_{0} e^{\frac{\varepsilon^{*}}{2} \tau_{0}}+1\right] \\
\leq \frac{M}{1-p_{0} e^{\frac{\varepsilon^{*}}{2} \tau_{0}}}\|\phi\|_{\left(\tau_{0}, \sigma_{0}\right)} e^{-\frac{\varepsilon^{*}}{2}\left(t-t_{0}\right)}
\end{gathered}
$$

Similarly, by (13), we obtain, for $t \in\left[t_{0}+\tau_{0}, t_{0}+2 \tau_{0}\right)$,

$$
\begin{aligned}
|x(t)| & \leq|p(t)| \mid x\left(t-\tau(t) \mid+M\|\phi\|_{\left(\tau_{0}, \sigma_{0}\right)} e^{-\frac{\varepsilon^{*}}{2}\left(t-t_{0}\right)}\right. \\
& \leq p_{0} M\|\phi\|_{\left(\tau_{0}, \sigma_{0}\right)} e^{-\frac{\varepsilon^{*}}{2}\left[t-\tau(t)-t_{0}\right]}\left[p_{0} e^{\frac{\varepsilon^{*}}{2} \tau_{0}}+1\right]+M\|\phi\|_{\left(\tau_{0}, \sigma_{0}\right)} e^{-\frac{\varepsilon^{*}}{2}\left(t-t_{0}\right)}
\end{aligned}
$$




$$
\begin{aligned}
& \leq p_{0} M\|\phi\|_{\left(\tau_{0}, \sigma_{0}\right)} e^{-\frac{\varepsilon^{*}}{2}\left(t-\tau_{0}-t_{0}\right)}\left[p_{0} e^{\frac{\varepsilon^{*}}{2} \tau_{0}}+1\right]+M\|\phi\|_{\left(\tau_{0}, \sigma_{0}\right)} e^{-\frac{\varepsilon^{*}}{2}\left(t-t_{0}\right)} \\
& \leq M\|\phi\|_{\left(\tau_{0}, \sigma_{0}\right)} e^{-\frac{\varepsilon^{*}}{2}\left(t-t_{0}\right)}\left[p_{0}^{2} e^{\frac{\varepsilon^{*}}{2} 2 \tau_{0}}+p_{0} e^{\frac{\varepsilon^{*}}{2} \tau_{0}}+1\right] \\
& \leq \frac{M}{1-p_{0} e^{\frac{\varepsilon^{*}}{2} \tau_{0}}}\|\phi\|_{\left(\tau_{0}, \sigma_{0}\right)} e^{-\frac{\varepsilon^{*}}{2}\left(t-t_{0}\right)} .
\end{aligned}
$$

By induction, we reach at, for $t \in\left[t_{0}+k \tau_{0}, t_{0}+(k+1) \tau_{0}\right), k \in Z_{+}$,

$$
\begin{aligned}
|x(t)| & \leq \mid p(t) \| x\left(t-\tau(t) \mid+M\|\phi\|_{\left(\tau_{0}, \sigma_{0}\right)} e^{-\frac{\varepsilon^{*}}{2}\left(t-t_{0}\right)}\right. \\
& \leq M\|\phi\|_{\left(\tau_{0}, \sigma_{0}\right)} e^{-\frac{\varepsilon^{*}}{2}\left(t-t_{0}\right)}\left[p_{0}^{k+1} e^{\frac{\varepsilon^{*}}{2}(k+1) \tau_{0}}+p_{0}^{k} e^{\frac{\varepsilon^{*}}{2} k \tau_{0}}+\ldots+p_{0} e^{\frac{\varepsilon^{*}}{2} \tau_{0}}+1\right] \\
& \leq \frac{M}{1-p_{0} e^{\frac{\varepsilon^{*}}{2} \tau_{0}}}\|\phi\|_{\left(\tau_{0}, \sigma_{0}\right)} e^{-\frac{\varepsilon^{*}}{2}\left(t-t_{0}\right)} .
\end{aligned}
$$
completed.

So, the inequality (12) holds. Thus, the zero solution of (5) is GES. Therefore the proof is

Corollary 1. Let $q_{1} n_{1}\left(1-p_{0}\right)>r_{2}\left(1+p_{0}\right)$. Then the zero solution of (5) is uniformly stable.

Proof. To show that the zero solution of equation (5) is uniformly stable, we consider the following Lyapunov functional:

$$
\begin{gathered}
V(t)=[x(t)+p(t) x(t-\tau(t))]^{2}+p_{0}\left(q_{1} n_{1}+r_{2}\right) \int_{t-\tau(t)}^{t} x^{2}(s) d s \\
+r_{2}\left(1+p_{0}\right) \int_{t-\sigma(t)}^{t} \tanh ^{2} x(s) d s .
\end{gathered}
$$

Then taking into account inequality $|p(t)| \leq p_{0}<1$ and using the similar argument to the proof of Theorem 1, we can obtain the above mentioned result.

Example 1. As a special case of (5), we take into account the following nonlinear equation system with two time-varying lags

$$
\begin{aligned}
& \frac{d}{d t}\left[x(t)+\frac{1}{6+t^{2}} x(t-\tau(t))\right]+(1+\exp (-t))\left[2 x+\frac{x}{1+x^{2}}\right] \\
& -\left(\frac{1}{4}+\exp (-t)\right) \tanh x(t-\sigma(t))=0, \quad t \geq 0 .
\end{aligned}
$$
written:

Here, considering the conditions (3), (4) and (7), the following equality or inequalities can be 


$$
\begin{aligned}
& p(t)=\frac{1}{6+t^{2}} \leq \frac{1}{6}=p_{0}<1, \\
& q_{1}=1 \leq q(t)=1+\exp (-t) \leq 2=q_{2}, \\
& r_{1} \leq \frac{1}{4}=r(t)=\frac{1}{4}+\exp (-t) \leq \frac{5}{4}=r_{2}, \\
& h(x)=2 x+\frac{x}{1+x^{2}}, \quad h_{1}(x)=\left\{\begin{array}{l}
2+\frac{1}{1+x^{2}}, \quad x \neq 0 \\
h^{\prime}(0), \quad x=0
\end{array}\right. \\
& h(0)=0, \quad n_{1}=2 \leq h_{1}(x) \leq 3=n_{2} \quad \tau^{2}(t)=\frac{\sin 2 t}{2} \leq \frac{1}{2}=\delta_{1}<1, \\
& 0 \leq \tau(t)=\frac{\sin ^{2}(t)}{2} \leq \frac{1}{2}=\tau_{0}, \tau^{\prime}(t)=\frac{\sin 2 t}{2} \leq \delta_{2}<1, \\
& 0 \leq \sigma(t)=\frac{\sin ^{2}(t)}{2} \leq \frac{1}{2}=\sigma_{0}, \sigma^{\prime}(t)=\frac{1}{2} \\
& \alpha=\frac{2}{3} \text { and } \beta=\frac{3}{2} .
\end{aligned}
$$

As seen in the example above, it is clear that the equation (14) under different initial conditions is stable after a certain time interval. Thus, all the conditions of Theorem 1 are provided.

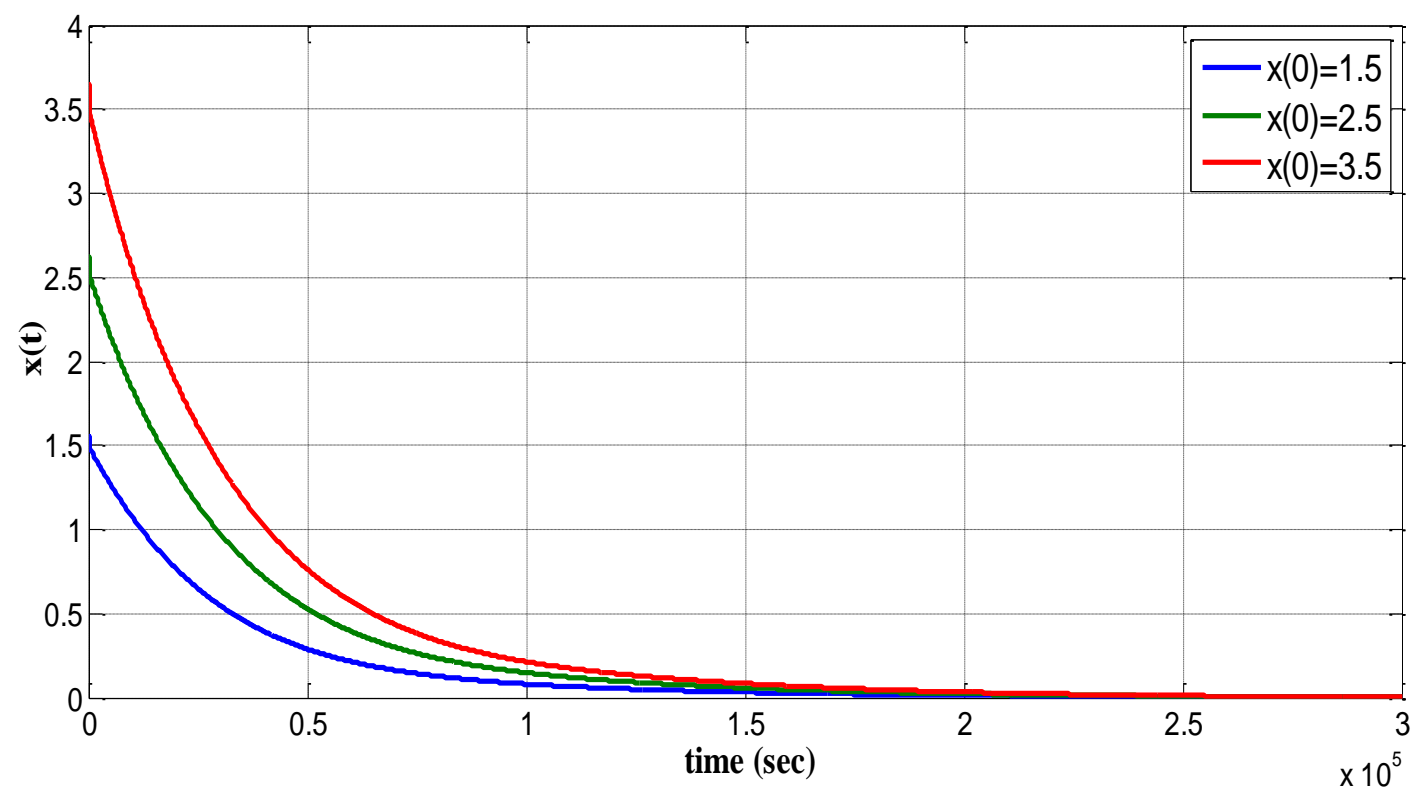

Figure. 1 Trajectories of $x(t)$ of equation (14) in Example 1, for $\tau(t)=\sigma(t)=\frac{\sin ^{2}(t)}{2}, t \geq 0$.

\section{Conclusion}

As a result, we examined the global exponential stability of the problem (2). An appropriate LyapunovKrasovskii functional was defined and stability criteria were obtained. An example is given to illustrate the feasibility and usefulness of the results obtained. The MATLAB-Simulink Program was used to illustrate the results of the problem presented in the example. The simulation of the example we consider as a special case of equation (2) is shown in Figure 1. When the Figure is examined it is clear that the equation considered in the example is stable after a certain time interval under different initial conditions. Our results include the results found in the relevant literature and improves them. 


\section{References}

[1] Agarwal R.P., Grace S.R. 2000. Asymptotic stability of certain neutral differential equations. Math. Comput. Modelling, 31 (8-9): 9-15.

[2] Altun Y., Tunç C. 2017. On the global stability of a neutral differential equation with variable time-lags. Bull. Math. Anal. Appl., 9 (4): 31-41.

[3] Cakir M., Arslan D. 2015. The Adomian decomposition method and the differential transform method for numerical solution of multi-pantograph delay differential equations. Appl. Math., 6: 1332-1343.

[4] Cao J. 2001. Global exponential stability of Hopfield neural networks. Internat. J. Systems Sci., 32 (2): 233-236.

[5] El-Morshedy H.A., Gopalsamy K. 2000. Nonoscillation, oscillation and convergence of a class of neutral equations. Nonlinear Anal. Ser. A: Theory Methods, 40 (1-8):173-183.

[6] Erbe L., Kong Q., Zhang B. 1995. Oscillation Theory for Functional Differential Equations. Marcel Dekker, New York.

[7] Fridman E. 2002. Stability of linear descriptor systems with delays a Lyapunov-based approach. J. Math. Anal. Appl., 273 (1): 24-44.

[8] Gopalsamy K. 1992. Stability and Oscillation in Delay Differential Equations of Population Dynamics. Kluwer Academic, Netherlands.

[9] Gopalsamy K., Leung I., Liu P. 1998. Global Hopf-bifurcation in a neural netlet. Appl. Math. Comput., 94: 171-192.

[10] Keadnarmol P., Rojsiraphisal T. 2014. Globally exponential stability of a certain neutral differential equation with time-varying delays. Adv. Difference Equ., 32, 10 pp.

[11] Kulenovic M., Ladas G., Meimaridou A. 1987. Necessary and sufficient conditions for oscillations of neutral differential equations. J. Aust. Math. Soc. Ser. B, 28: 362-375.

[12] Li X. 2009. Global exponential stability for a class of neural networks. Appl. Math. Lett., 22 (8): 1235-1239.

[13] Mohamad S., Gopalsamy K. 2000. Dynamics of a class of discrete-time neural networks and their continuous-time counterparts. Math. Comput. Simulation, 53: 1-39.

[14] Park J.H. 2004. Delay-dependent criterion for asymptotic stability of a class of neutral equations. Appl. Math. Lett., 17 (10): 1203-1206.

[15] Park J.H., Kwon, O. M. 2008. Stability analysis of certain nonlinear differential equation. Chaos Solitons Fractals, 37: 450-453.

[16] Tunç C. 2015. Convergence of solutions of nonlinear neutral differential equations with multiple delays. Bol. Soc. Mat. Mex., 3 (21): 219-231.

[17] Tunç, C., Altun, Y. 2016. Asymptotic stability in neutral differential equations with multiple delays. J. Math. Anal., 7 (5): 40-53.

[18] Xu S., Lam J. 2006. A new approach to exponential stability analysis of neural networks with time-varying delays. Neural Netw., 19: 76-83. 